\section{Protection against Propaganda}

Science Service of Washington, D.C., has published under the title "Propaganda Protection" a series of short articles forming an exposition of the methods and aims of war propaganda. The chemist and physicist are frequently criticized for discovering poison gases and high explosives, but without the will of the fighter the destructive compounds would be powerless. The aim of the propagandist is to make people willing to act in a particular way, and his general means are the arousal of emotion and the stifling of reason. The specific methods are the appeal to prejudice and hate by the use of slogans, by the demand for haste since delay may bring reason into play, by the use of statements that can neither be proved nor disproved, by concealing the source of the statements, and by persuading the hearer or reader to associate particular evils, for example, conspiracy, plotting, oppression, injustice, and particular virtues, for example, bravery, sympathy, humanity, patriotism, with some particular creed, party, or country. The propagandist knows the weaknesses of mankind and in many cases consciously exploits them for his own ends. The general methods are not new in the history of mankind, but the development of the means of communication by travel and radio has made all of us much more vulnerable to the propagandist attack. It is com. monly asserted that more knowledge is the best immunizing agent against propaganda; but to be effective we need much more knowledge of our own mental make-up, as well as greater knowledge of facts outside ourselves. It is unfortunate that our knowledge of psychology lags so far behind our knowledge of other aspects of reality.

\section{Physical and Mental Welfare Society of New Zealand}

ON July 22 last, a body known as the Physical and Mental Welfare Society of New Zealand was formally incorporated; the object of the Society is, broadly, to promote the application of current scientific knowledge to physical and mental welfare. The Society originated in a movement which has existed and operated throughout the Dominion for several years. It was promoted by a group of voluntary workers in the social services, under the leadership of Mrs. Ysabel Daldy, who has hitherto worked under the noms de plume of "Mother Machree" and "Silent Peter". In numerous weekly articles contributed to some twenty New Zealand newspapers, she has interpreted current scientific knowledge in its bearings on social welfare to the general reader in simple and attractive language, thus moulding public opinion and preparing the way for necessary reforms. She has been assisted by the "Silent Peter" group of specialist advisers, which is stated to include representatives of the medical profession and others well qualified severally to advise and write on health, nutrition, agriculture, education and some branches of science. Through her articles in newspapers and by correspondence with Government departments and with individuals, Mrs. Daldy has done valuable work in guiding and stimulating public opinion, and the increased opportunities afforded by the new Society of reaching the public by lectures, publications and other means, should enable this body of scientific opinion to exert its full influence in promoting the application of seience to social problems in New Zealand.

\section{Archæological Investigations in the Hadramaut}

FuRTHER details of archæological investigations in the Hadramaut of southern Arabia were given by Miss G. Caton-Thompson in a lecture before the Royal Geographical Society on November 7, in which she described the results of the expedition undertaken by Miss Elinor W. Gardner, Miss Freya Stark and herself in the winter of 1937-38. The uniform, but crude character of the palæolithic industry of the region, to which she referred in her preliminary report (see Nature, 142, 139, July 23, 1938) was again emphasized. This industry falls well within the limits of the Levallois flake industry; but its crudity is strikingly apparent on comparison with the corresponding industries of Africa, North Arabia and Palestine. It represents a low ebb in contemporary standards, which Miss Caton-Thompson is inclined to attribute either to the influence of a harsh and impoverished environment, or possibly to the absence of technical stimulus from contact with more progressive groups, such as, for example, might have been supplied from East Africa. The latter alternative postulates the separation at an early date in the Pleistocene or before of south-west Arabia from East Africa. The conception of an early marine separation of the two regions is reinforced by the fact that of the three culture groups classified morphologically by the hand-axe, the flake, and the blade industries, the hand-axe culture group, which covers practically the whole of Africa, failed, so far as the evidence goes, to reach south-west Arabia. The huge numbers of flint implements of Levallois type argues a status quo so far back as the middle or later Pleistocene. Of the evidenee of plant life found in the tufa in the Wadi Luqrun, absence of structure makes identification impossible ; but one is a species of Celtis, another type, the commonest, resembles the fig in leaf; and some kind of palm is certainly present.

\section{The Government Laboratory}

SEVENTEen THoUsand samples in excess of the number submitted in the previous year are recorded in the report of the Government Chemist as having been examined in the year ended March 31, 1938. The total number was substantially larger than half a million. The work of the Laboratory, however, is not to be measured by numbers alone, for it involves much research into the reliability of existing methods of analysis, and many investigations into new methods of detection and determination of substances. Further, the staff is constantly being consulted on technical matters, while, in addition, its members contribute notably to the advance of pure and applied chemistry both by publication and by personal service 
on numerous committees. In its analysis of the results of the examination of 848 samples of imported butter, the report shows that the water content of considerably more than half of the samples was between 15 and 16 per cent; the Reichert value of the fat varied from $24 \cdot 0$ to $34 \cdot 0$ (in 555 cases from 28 to 32 ), while the Polenské value varied from $1 \cdot 0$ to $3 \cdot 35$. Of 87 samples of tinned cream, 81 contained between 20 and 29 per cent of fat ; of 127 samples of cheese, 17 per cent had been prepared from milk containing less than one half of its fat. In neither case is it at present possible to take exception to such im. portations. The examination of water included sea water studies for the use of hydrographers and biologists, on rivers in connexion with fish and fish food, and on water-cress beds in relation to the use of the national mark. Of 2,270 samples of brewing materials, 18 contained arsenic in slight excess of the accepted limit. It is satisfactory to learn that owing to the stringency of the tobacco laws and the high standard of the tobacco industry in Great Britain, adulteration is almost non-existent. The Laboratory has also been concerned with such widely different matters as the pollution of foreshores, the manipulation of radioactive materials, the carriage of dangerous cargo, and the work of the Bed-bug Infestation Committee.

\section{Carrier Telephony}

AN instructive address on carrier telephony was delivered to the London Students Section of the Institution of Electrical Engineers, on October 31, by its chairman, P. H. Pettifor. The frequencies present in the normal speech range are included between the limits 75-9000 cycles per sec., but for intelligible and 'natural' speech, it is only necessary for the listener to hear a very small portion of that spectrum, and in normal telephone practice the range lying between 300 to 2700 cycles per second only is used. This possible restriction in the range necessary for satisfactory speech is fully utilized in carrier telephony. The lower the frequency of the transmitted band the greater the number of channels which can be accommodated for that band. A carrier-current telephone system is one in which the normal vaice frequencies are raised to a band of higher frequencies before being transmitted over the open-wire line or cable, conversion to the normal voice frequency band taking place at the receiving station. If different circuits have their voice frequencies raised by amounts such that the high-frequency bands do not overlap one another, then one cable pair can be used to transmit speech to several circuits, without the circuits interfering with one another. In this way the signals in several circuits can be transmitted over one cable pair without any interference taking place. The development of the principles of carrier telephony has been slow; the early experiments were made by Ruhmer in 1909 , before the present-day thermionic devices were developed. A brief description was given of the postWar development in this field, including the latest cable design technique. Amongst the types of cable described was a cable containing a pair of air-spaced self-locating conductors. This type of cable is laid around London for television purposes. Another type containing four coaxial conductors has been laid between London and Birmingham. A similar coaxial cable containing only one coaxial conductor insulated with para-gutta has also been found very useful. With modern systems the level of cross talk between channels is practically negligible when compared with the normal voice frequency systems.

\section{A 'New Deal' in Education}

President Roosevert's Advisory Committee on Education, appointed in September 1936, has presented a report (Government Printing Office, Washington, 1938. Pp. 244. 35 cents) on the whole subject of Federal relationship to State and local conduct of education. After a comprehensive study of the entire field of educational service, the committee found that there is great need for improvement of the public schools in a number of broad geographical regions and in the rural areas generally. To redress the existing gross inequalities of educational opportunity it submits a set of carefully articulated proposals forming, as is justly claimed, "a unified and coherent pattern of Federal policy" and involving a six years plan for Federal grants for educational services amounting in the aggregate to 1,200 million dollars. Most of the new grants recommended fall under the headings : general aid to elementary and secondary education, preparation of teachers and other educational personnel, school buildings, administration of State departments of education, educational services for adults, library service for rural areas. A system of co-operative research accompanied by demonstration projects throughout the country has proved its value in the field of agriculture, and the committee recommends the establishment of a special Federal fund for the immediate application of such a system in the field of education. In the first instance it would be utilized especially for elucidating in advance problems bound to arise in connexion with the operation of the six years plan for Federal grants.

\section{The Colombo Museum}

THE administration report for 1937 of the acting director of the Colombo Museum, P. E. P. Deraniyagala, shows that in many directions the activity of the museum is maintained. Steady additions are being made to the zoological collections, notably by expeditions carried out by the staff or by the staff jointly with representatives of the British Museum, so that the director considers that the accumulation of material is now sufficient to justify the publication of detailed monographs. At the same time, attention ought to be directed to the public galleries, and the replacement of the misleading and faded specimens in the bird gallery would doubtless be appreciated by the half-million visitors who pass through the galleries each year and especially by the large number of school-children $(12,288)$ who make use of the exhibits in the course of their nature study instruction. 